\title{
FREE VIBRATIONAL ANALYSIS OF CURVED BEAM WITH UNIFORM RECTANGULAR CROSS SECTION
}

\author{
Hanumantharaju H G' ${ }^{1}$, Motupalli Jayaprasad ${ }^{2}$ \\ ${ }^{I}$ Assistant professor, Mechanical engineering, University Visweshwaraya College of Engineering, Karnataka, India. \\ Email: hghuvce@gmail.com \\ ${ }^{2}$ M.E Scholar Mechanical engineering, University Visweshwaraya College of Engineering, Karnataka, India.
} Email: motupalli.prasad@gmail.com

\begin{abstract}
Curved beams are plays an important role in different field like house roofing, bridges, cranes, automobiles chasses etc. The study deals with the investigation of free vibrations of thick curved beams of SS316 and MS1018, both experimentally and using ANSYS. The curved beams having different $R / t$ ratio were fabricated by using mild steel material. Three different boundary conditions are imposed for curved beams are as follows; free-free, clamped-free, clamped-clamped. For experimental investigation, magnetic transducer and VIBXpert are used to conduct experiment on different curved beams. The present work also aims at developing a numerical model for comparing ANSYS results with experimental results to analyze the frequencies and mode shapes corresponding to three different boundary conditions. The curved beam were modelled, meshed and analyzed using ANSYS. The first ten natural frequencies from finite element solutions are then compared with the experimental results. These effects also become more significant for higher modes. It is also observed that the finite element solutions are closely in agreement with experimental results.
\end{abstract}

Key words: Curved beams, Experimental investigation, Natural frequencies, modes $* * *$

\section{INTRODUCTION}

Arch elements occur frequently in many engineering applications such as spring design, electrical machinery, turbo-machinery blades, circumferential stiffeners for shells and aerospace structures in mechanical engineering and the design of arch bridges [1], highway construction, long span roof structures and earthquake resistant structures in civil engineering. Therefore, the analysis of arches is of great importance and has received considerable attention since the end of the nineteenth century.

In straight beams the neutral curved axis of the section coincides with its centroidal axis and the stress distribution in the beam is linear [2]. But in case of curved beams the neutral axis of the section is shifted towards the centre of curvature of the beam causing a non-linear [hyperbolic] distribution of stress [3]. The neutral axis lies between the centroidal axis and the centre of curvature and will always be present within the curved beams.

\subsection{Curved Beam Application}

It is well established that curved beams are more efficient than straight beams since they are capable of transferring loads through the combined action of bending and stretching.

Figure 1 shows the application of curved beam.

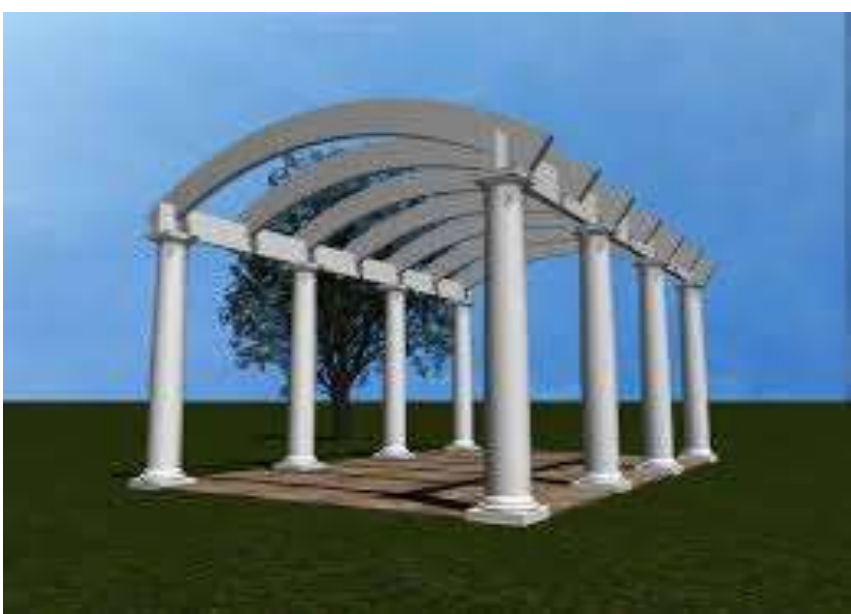

Figure 1: Curved beam in bridges

The study of curved beams becomes significant as the same could provide some insight into the behaviour of shell element developed on similar basis [4]. Also element used for beams cannot be extended to analyze the shells unless it works correct [5].

\subsection{Material Selection}

\subsubsection{Mild Steel 1018}

Mild steel also known as plain-carbon steel, is now the most common form of steel because its price is relatively low while it provides material properties that are acceptable for many applications. 
Table 1. Chemical composition of mild steel

\begin{tabular}{|c|c|c|c|c|}
\hline $\begin{array}{c}\text { Iron } \\
(\mathbf{F e})\end{array}$ & $\begin{array}{c}\text { Carbon } \\
(\mathbf{C})\end{array}$ & $\begin{array}{c}\text { Manganese } \\
(\mathbf{M n})\end{array}$ & $\begin{array}{c}\text { Phosphorus } \\
(\mathbf{P})\end{array}$ & $\begin{array}{c}\text { Sulfur } \\
(\mathbf{S})\end{array}$ \\
\hline $\begin{array}{c}98.81- \\
99.26 \%\end{array}$ & $0.17 \%$ & $0.6-0.9 \%$ & $0.04 \% \max$ & $\begin{array}{c}0.05 \% \\
\max \end{array}$ \\
\hline
\end{tabular}

\subsubsection{SS316}

Most Commonly used steel in structures is type 316 steel, molybdenum-alloyed steel and most common austenite stainless steel. It is mainly used in marine environments because of its greater resistance to pitting corrosion than other grades of steel.

Table 2. Represents the Chemical composition of SS316

\begin{tabular}{|c|c|c|c|c|c|c|c|c|c|}
\hline SAE & $\% \mathrm{Cr}$ & $\% \mathrm{Ni}$ & $\% \mathrm{C}$ & $\% \mathrm{Mn}$ & $\% \mathrm{Si}$ & $\% \mathbf{P}$ & $\% \mathrm{~S}$ & $\% \mathrm{~N}$ & $\% \mathrm{Mo}$ \\
\hline 316 & $\begin{array}{l}16- \\
\text { I8 }\end{array}$ & $\begin{array}{c}10- \\
14\end{array}$ & 0.08 & 2 & 0.75 & 0.045 & 0.03 & 0.10 & $\begin{array}{c}2.0- \\
3.0\end{array}$ \\
\hline
\end{tabular}

\section{EXPERIMENTATION}

In a modal analysis test, vibration force has applied to the structure. Exciter system or hammer impact serves this purpose. Vibration motion is measured by using magnetic transducer. These signals are processed by an analysis system that will digitize them and used them for estimation of frequency response function. This procedure is repeated for several excitation and response combinations. Experimental set up for clamped-clamped vibration is shown in figure 2.

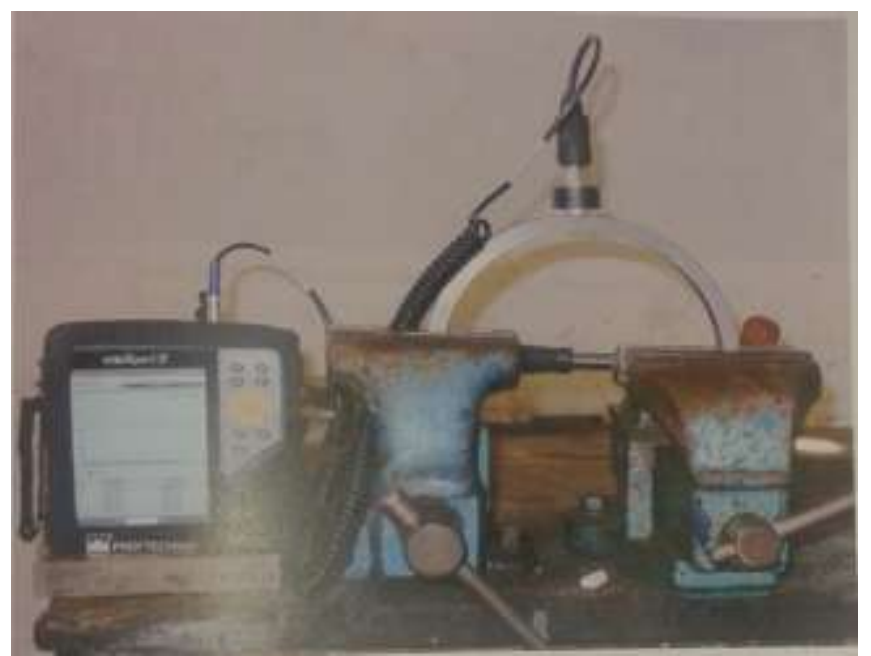

Figure 2: Clamped-clamped vibration setup

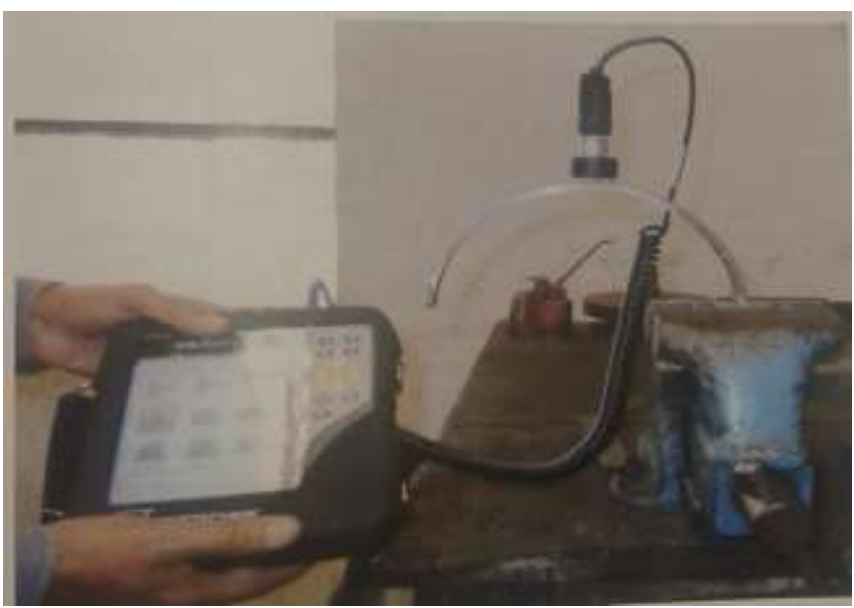

Figure 3: Clamped-free vibration setup

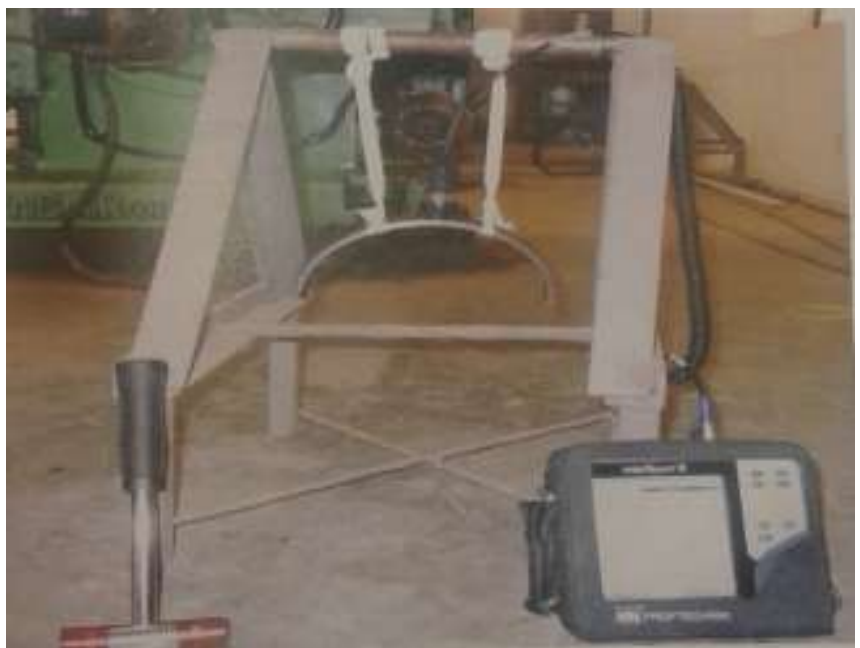

Figure 4: Free-Free vibration setup

The curved beam was subjected to clamped-clamped, clamped-free and free-free conditions by using supports (Fixtures and vices).

2.1 Magnetic Transducer: In most modal analysis measurements magnetic transducers replaced the more classical dynamometers with strain gauges. The force acting on the transducer deforms the piezoelectric crystal, thus generating a charge over the crystal. The main characteristics are the maximum force minimum and maximum frequency (which depends on the load) and sensitivity.

\section{VIBRATIONAL ANALYSIS USING ANSYS}

The geometric models of thick, moderately thick and thin curved beams are created in ANSYS using solid95 element. The thick curved beam is divided into 750 elements and 4362 nodes. The thin curved beam is divided into 250 elements and 2028 nodes. Discretised thick beam is shown in figure 5 


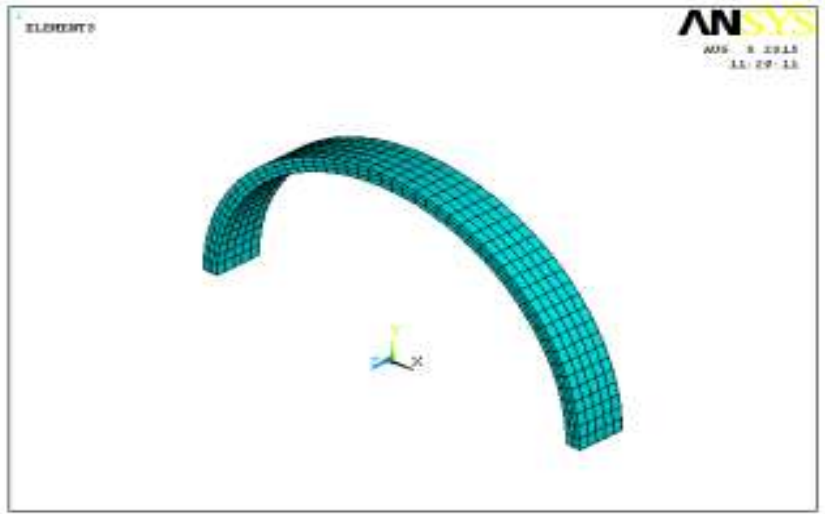

Figure 5: Discretised thick curved beam

\subsection{Boundary Conditions}

Boundary conditions are applied to the curved beams (Thick and thin) at their ends. Each curved beam is subjected to four different boundary conditions.

1. Clamped-Clamped condition

2. Clamped-Free condition

3. Free-Free condition

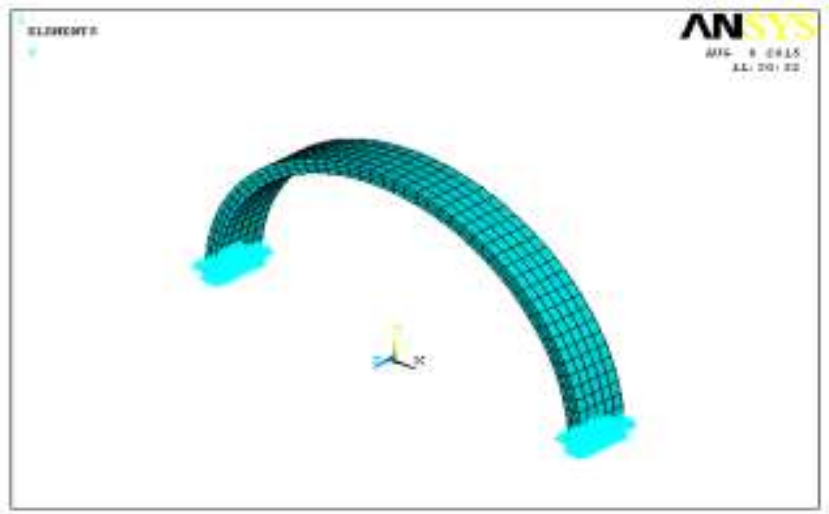

Figure 6: Clamped-clamped conditions

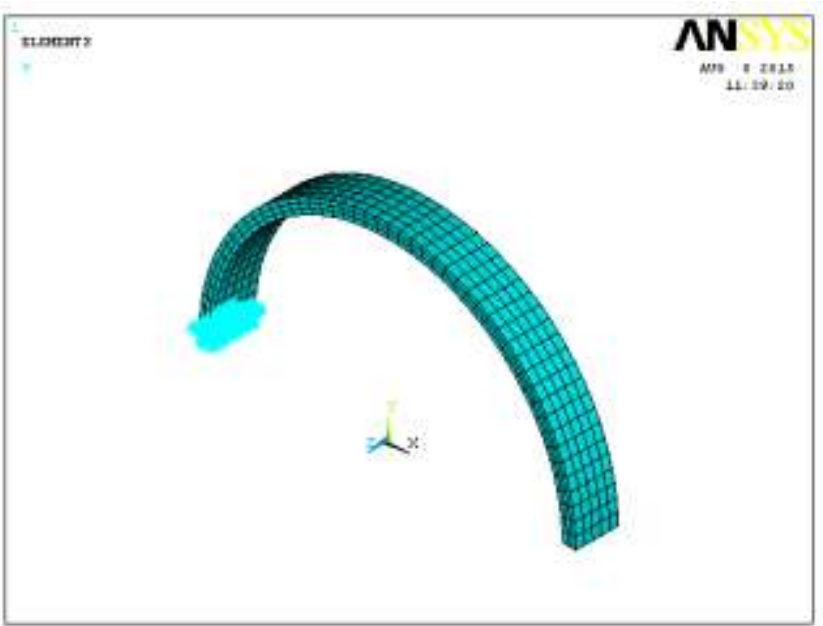

Figure 7: Clamped-Free conditions

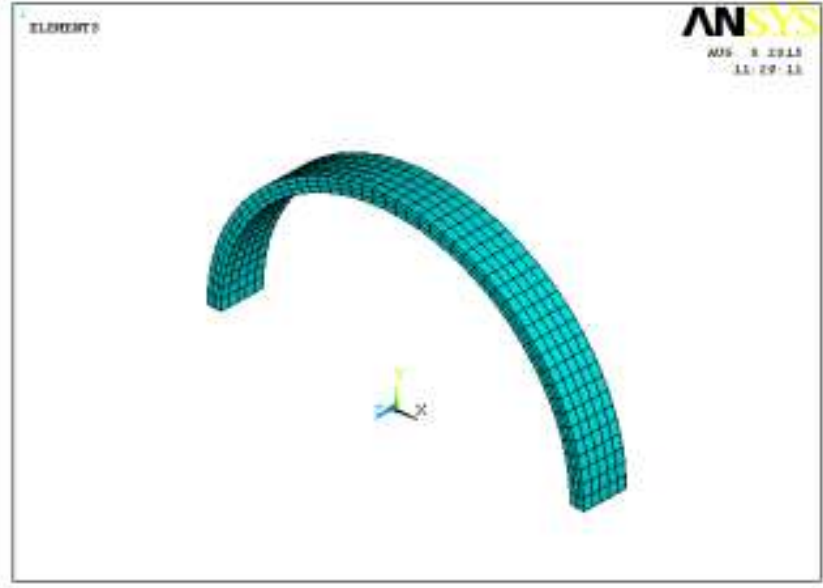

Figure 8: Free-Free conditions

\section{RESULTS}

\subsection{Analysis of Thick Beam at Clamped-Clamped}

\section{Condition}

Figure 9 represents the mode shape of clamped-clamped boundary condition for mild steel1018.

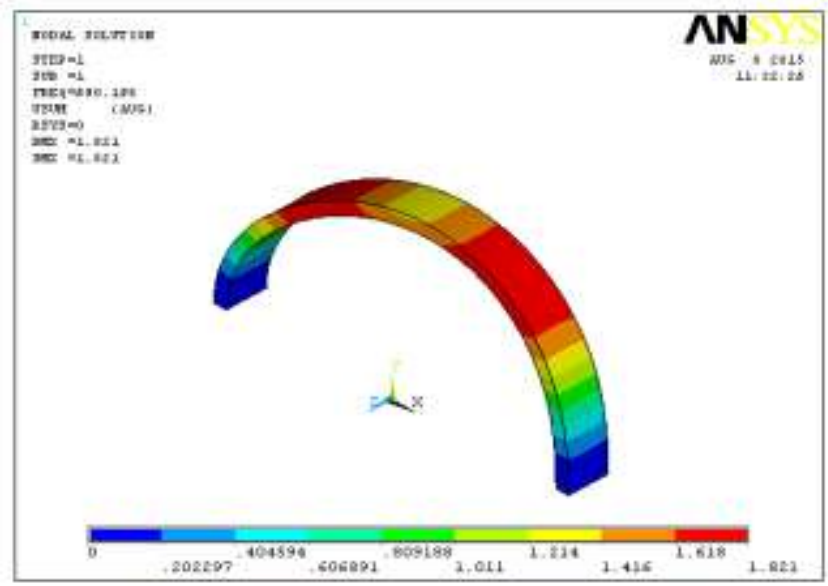

Figure 9: Mode shape and natural frequency $690.20 \mathrm{~Hz}$ for Clamped-Clamped condition.

Table 3. Shows the natural frequencies at different mode shapes.

\begin{tabular}{|c|c|c|c|}
\hline $\begin{array}{c}\text { Mode } \\
\text { No. }\end{array}$ & $\begin{array}{c}\text { ANSYS } \\
\text { Results } \\
\text { in Hz }\end{array}$ & $\begin{array}{c}\text { Experimental } \\
\text { Results in Hz }\end{array}$ & $\begin{array}{c}\text { Percentage } \\
\text { Error }\end{array}$ \\
\hline 1 & 690.20 & 729.5 & 5.64 \\
\hline 2 & 762.33 & 794 & 4.16 \\
\hline 3 & 1498.8 & 1545 & 3.17 \\
\hline 4 & 2089.3 & 2137 & 2.20 \\
\hline 5 & 2769.1 & 2792 & 0.83 \\
\hline 6 & 4141.7 & 4202 & 1.48 \\
\hline 7 & 4162.9 & 4304 & 3.41 \\
\hline 8 & 5981.3 & 6108 & 2.13 \\
\hline 9 & 6803.6 & 6856 & 0.77 \\
\hline 10 & 6845.6 & 6989 & 2.1 \\
\hline
\end{tabular}


Table 4. Represents the comparison of natural frequencies between mild steel 1018 and SS316

\begin{tabular}{|c|c|c|}
\hline $\begin{array}{c}\text { Mode } \\
\text { No. }\end{array}$ & $\begin{array}{c}\text { SS316 } \\
\text { Thick beam } \\
\text { results in Hz }\end{array}$ & $\begin{array}{c}\text { MS1018 } \\
\text { Thick beam } \\
\text { results in Hz }\end{array}$ \\
\hline 1 & 786.25 & 690.20 \\
\hline 2 & 970.09 & 762.33 \\
\hline 3 & 2075.3 & 1498.8 \\
\hline 4 & 2146.8 & 2089.3 \\
\hline 5 & 3810.7 & 2769.1 \\
\hline 6 & 4302.4 & 4141.7 \\
\hline 7 & 5379.5 & 4162.9 \\
\hline 8 & 7045.3 & 5981.3 \\
\hline 9 & 7180.8 & 6803.6 \\
\hline 10 & 7194.0 & 6845.6 \\
\hline
\end{tabular}

Figure 10 shows the numerical comparison between mild steel1018 and SS316 thick curved beam at clamped-clamped condition.

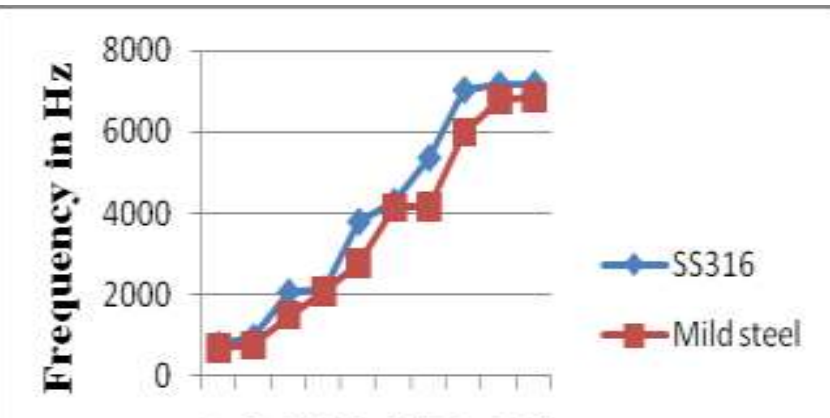

12345678910

\section{ModeNo.}

Figure 10: Numerical comparisons between mild steel1018 and SS316.

\subsection{Analysis of thick beam at Clamped-Free Condition}

Figure 11 represents the mode shape of clamped-Free boundary condition for mild steel1018.

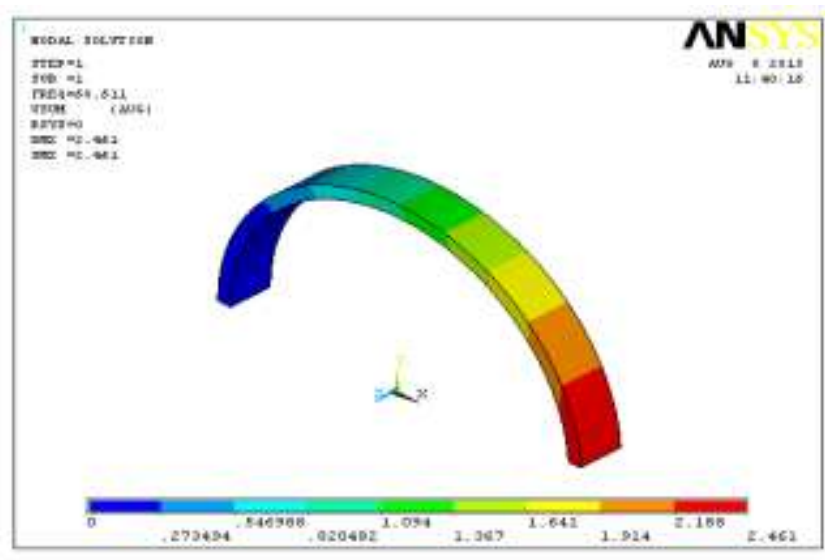

Figure 11: Mode shape and natural frequency $68.61 \mathrm{~Hz}$ for Clamped-Free condition.

Table 5. Shows the natural frequencies at different mode

\begin{tabular}{|c|c|c|c|}
\hline $\begin{array}{c}\text { Mode } \\
\text { No. }\end{array}$ & $\begin{array}{c}\text { ANSYS } \\
\text { Results } \\
\text { in Hz }\end{array}$ & $\begin{array}{c}\text { Experimenta } \\
\text { 1 Results in } \\
\mathrm{Hz}\end{array}$ & $\begin{array}{c}\text { Percentage } \\
\text { Error }\end{array}$ \\
\hline 1 & 68.611 & 73.5 & 7.14 \\
\hline 2 & 95.133 & 101 & 5.94 \\
\hline 3 & 216.70 & 237 & 9.35 \\
\hline 4 & 450.54 & 489 & 8.68 \\
\hline 5 & 738.42 & 803 & 8.70 \\
\hline 6 & 1492.8 & 1600 & 7.23 \\
\hline 7 & 1638.6 & 1804 & 10.1 \\
\hline 8 & 2841.4 & 3001 & 5.62 \\
\hline 9 & 3268.6 & 3510 & 7.42 \\
\hline 10 & 4330.6 & 4520.5 & 4.32 \\
\hline
\end{tabular}

Table 6. Represents the comparison of natural frequencies Between mild steel 1018 and SS316

\begin{tabular}{|c|c|c|c|}
\hline $\begin{array}{c}\text { Mode } \\
\text { No. }\end{array}$ & $\begin{array}{c}\text { ANSYS } \\
\text { Results } \\
\text { in HZ }\end{array}$ & $\begin{array}{c}\text { Experimental } \\
\text { Results in Hz }\end{array}$ & $\begin{array}{c}\text { Percentage } \\
\text { Error }\end{array}$ \\
\hline 1 & 24.65 & 26.2 & 6.50 \\
\hline 2 & 45.11 & 47 & 4.18 \\
\hline 3 & 69.76 & 73 & 4.64 \\
\hline 4 & 88.36 & 90 & 1.87 \\
\hline 5 & 128.43 & 134 & 4.36 \\
\hline 6 & 164.12 & 168 & 2.31 \\
\hline 7 & 288.48 & 292 & 1.12 \\
\hline 8 & 831.40 & 852 & 2.42 \\
\hline 9 & 1022.7 & 1040 & 0.94 \\
\hline 10 & 1733.3 & 1749 & \\
\hline
\end{tabular}


Table 7. Represents the comparison of natural frequencies between mild steel 1018 and SS316

\begin{tabular}{|c|c|c|}
\hline $\begin{array}{c}\text { Mode } \\
\text { No. }\end{array}$ & $\begin{array}{c}\text { SS316 Thick } \\
\text { beam results in } \\
\mathrm{Hz}\end{array}$ & $\begin{array}{c}\text { MS Thick beam } \\
\text { results in Hz }\end{array}$ \\
\hline 1 & 99.243 & 68.611 \\
\hline 2 & 125.31 & 95.133 \\
\hline 3 & 315.18 & 216.7 \\
\hline 4 & 522.15 & 450.54 \\
\hline 5 & 1067.5 & 1492.8 \\
\hline 6 & 1700.9 & 1638.6 \\
\hline 7 & 2345.3 & 2841.4 \\
\hline 8 & 3657.7 & 3268.6 \\
\hline 9 & 4012.8 & 4330.6 \\
\hline 10 & 5589.6 & \\
\hline
\end{tabular}

Figure 12 shows the numerical comparison between mild steel1018 and SS316 thick curved beam at clamped-Free condition.

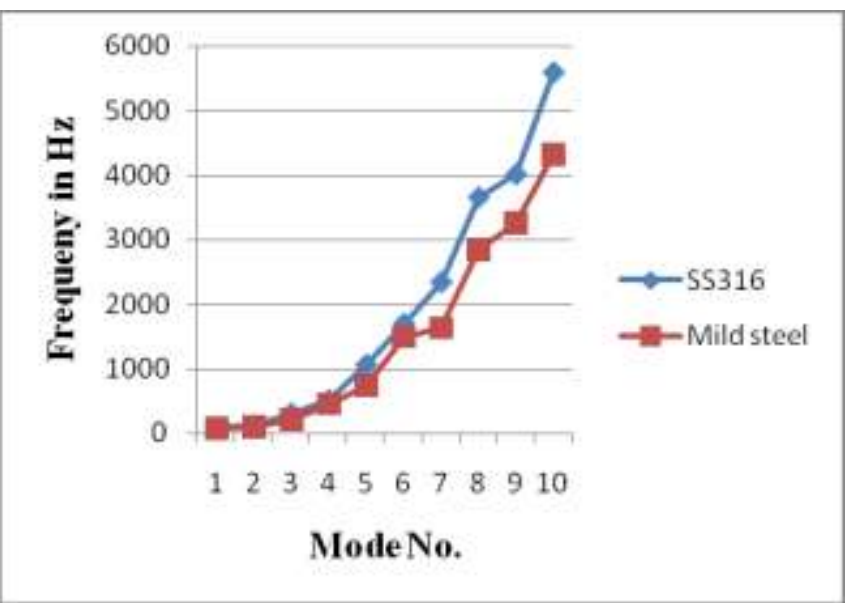

Figure 12: Numerical comparisons between mild steel1018 and SS316

\subsection{Analysis of thick beam at Free-Free Condition}

Figure 13 represents the mode shape of Free-Free boundary condition for mild steel1018.

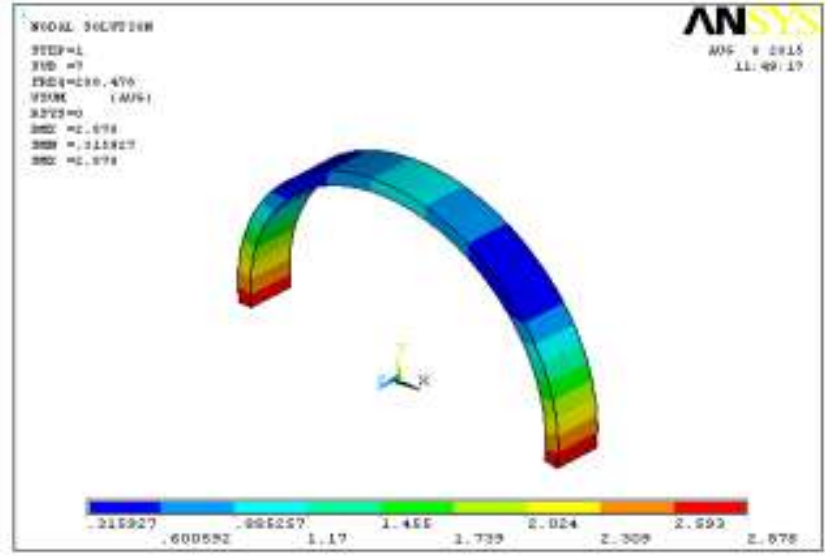

Figure 13: Mode shape and natural frequency $288.48 \mathrm{~Hz}$ for Free-Free condition

Table 8. Represents the comparison of natural frequencies between mild steel 1018 and SS316

\begin{tabular}{|c|c|c|}
\hline $\begin{array}{c}\text { Mode } \\
\text { No. }\end{array}$ & $\begin{array}{c}\text { SS316 Thick } \\
\text { beam results in } \\
\mathrm{Hz}\end{array}$ & $\begin{array}{c}\text { MS Thick beam } \\
\text { results in Hz }\end{array}$ \\
\hline 1 & 72.12 & 58.65 \\
\hline 2 & 94.65 & 85.11 \\
\hline 3 & 128.89 & 99.76 \\
\hline 4 & 165.50 & 135.36 \\
\hline 5 & 229.90 & 188.43 \\
\hline 6 & 301.23 & 234.12 \\
\hline 7 & 410.36 & 288.48 \\
\hline 8 & 1177.9 & 1022.7 \\
\hline 9 & 1286.1 & 1733.3 \\
\hline 10 & 2440.5 & \\
\hline
\end{tabular}

Figure 14 shows the numerical comparison between mild steel1018 and SS316 thick curved beam at Free-Free condition

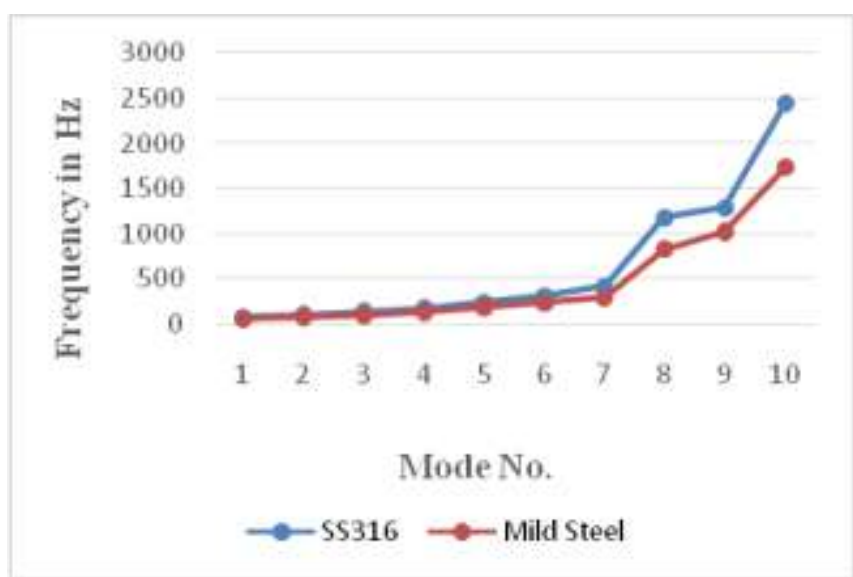

Figure 14: Numerical comparisons between mild steel1018 and SS316 


\section{CONCLUSIONS}

$>$ From Experiment and analysis, it is observed that only $5.64 \%$ error taken place in MS1018 thick curved beam at clamped-clamped condition which is acceptable.

$>$ From three different boundary conditions i.e. FreeFree, Clamped-Free and Clamped-Clamped, observed that maximum frequencies of 6989 and $7194 \mathrm{~Hz}$ in MS1018 and SS316 thick beam at clamped-clamped condition respectively.

$>$ It is also observed that, more vibration is generated in SS316, i.e. $4.84 \%$ more vibration at Clamped-Clamped condition.

\section{REFERENCES}

[1] S.Y. Lee and J.C. Chao, 2000, "out of plane vibrations of curved non-uniform beam of constant radius", Journal of Sound and Vibration, V-238, Pp-458.

[2] A.Krishnan and Y.J.Suresh, 1998, "A simple cubic linear element for static and free vibration analyses of curved beams", Journals of computers and structures, V-68, Pp-473-489.

[3] EkremTufekci and OznurOzdemirci, 2006, "Exact solution of free in-plane vibration of a stepped circular arch", Journal of Sound and Vibration, V-295, Pp-725738.

[4] Z.H. Zhu and S.A. Meguid, 2008, "vibration analysis of a new curved beam element", Journal of Sound and Vibration, V-309, Pp-86-95.

[5] F. Yang, R. Sedaghati and E. Esmailzadeh, 2008, "Free in-plane vibration of general curved beam using finite element method", Journal of Sound and Vibration, V318, Pp-850-867. 